\title{
Details of the rupture kinematics and mechanisms of the 1980 Irpinia earthquake: new results and remaining questions
}

\author{
Pascal Bernard $\left({ }^{1}\right)$, Aldo Zollo $\left({ }^{2}\right)$, Cezar-Ioan Trifu $\left({ }^{3}\right)$ and André Herrero $\left({ }^{1}\right)$ \\ (1) Institut de Physique du Globe de Paris, France \\ ${ }^{2}{ }^{2}$ Dipartimento di Geofisica e Vulcanologia, Università di Napoli, Italia \\ (') Center of Earth Physics and Seismology, Bucharest, Romania
}

\begin{abstract}
This paper focuses on the main results obtained by Bernard and Zollo (BZ), concerning the constraints on the location and mechanisms of the «20 s» and the «40 s» events of the Irpinia 1980 sequence, and providing an estimate of the absolute time at the 10 closest SMA1 accelerometers. It then includes some results of a recent analysis by Trifu et al. concerning the northwestern propagation of the « $0 \mathrm{~s} »$ event. Finally, in view of all the published analyses of this earthquake until now, we propose an updated sketch of the rupture, highlighting what we believe are now reliable results, as well as what we consider as being open major questions about the kinematics of the rupture and the focal mechanisms.
\end{abstract}

Bernard and Zollo $(1987,1989)$ made a detailed analysis of the near-source strong-motion data and the leveling profiles, in view of previously published work on the surface breakage by Westaway and Jackson (1984), leveling data by Arca et al. (1983) and Crosson et al. (1986), aftershock analysis by Deschamps and King (1984), moment tensor inversion by Boschi et al. (1981) and Kanamori and Given (1982), and teleseismic waveform modeling by Westaway and Jackson (1987) (WJ) (see fig. 1).

The first problem faced in constraining the kinematics of the rupture was the absence of absolute time on the accelerograms. We therefore located the $40 \mathrm{~s}$ hypocenter relative to the $0 \mathrm{~s}$ event by using the arrival time of the $S$ phases at $\mathrm{CAL}$ and BAG (S40), and of $P$ phases at BIS and CAL (P40). Some $S 40$ phases are presented in fig. 2 (top) for BAG, BIS, CAL and STU. The resulting location, about $10 \mathrm{~km} \mathrm{~N}-\mathrm{NE}$ to the first-event epicenter, in agreement with the location by WJ, is associated with an uncertainty of about $5 \mathrm{~km}$ in a NS direction, and $3 \mathrm{~km}$ in the EW direction. The hypocentral depth is between 5 and $8 \mathrm{~km}$.

The observed arrival time of the $S 40$ phases at 10 SMA1 stations allowed us to estimate their triggering time (top table in fig. 2), and the $S$ and $P$ arrival times of the first event $(S 0$ and $P 0$ ) with respect to the triggering (bottom table in fig. 2). Most of the stations triggered less than $2 \mathrm{~s}$ after the $P 0$ arrival.

In contrast, the triggering time $t_{0}$ at AUL and BRI was very late, significantly after the $S O$ arri$\operatorname{val}\left(t_{0}=S 0+3.5 \mathrm{~s}\right)$, which strongly suggests that the first rupture propagated less than $10 \mathrm{~km}$ towards the SE. These two stations, together with TRI, show a strong high-frequency horizontal phase, which was interpreted by $\mathrm{BZ}$ as the $S$ phase of the 20 s event (S20) (fig. 3, top), whose long-period radiation is clearly observed on the teleseismic records. The identification of the $S 20$ phase provides an epicentral location $15 \mathrm{~km}$ to the SE of the first-event epicenter, near the surface rupture of the San Gregorio Magno (uncertainty of about $7 \mathrm{~km}$ ). This location significantly differs from the location proposed by WJ, based on long-period teleseismic data, and hence associated with much larger uncertainties. The subsidence observed on a $10 \mathrm{~km}$ long segment of the southern leveling line (fig. 3, bottom) gives evidence for a southern propagation of the $20 \mathrm{~s}$ rupture, as was independently suggested by the strong acceleration recorded at BRI (horizontal 


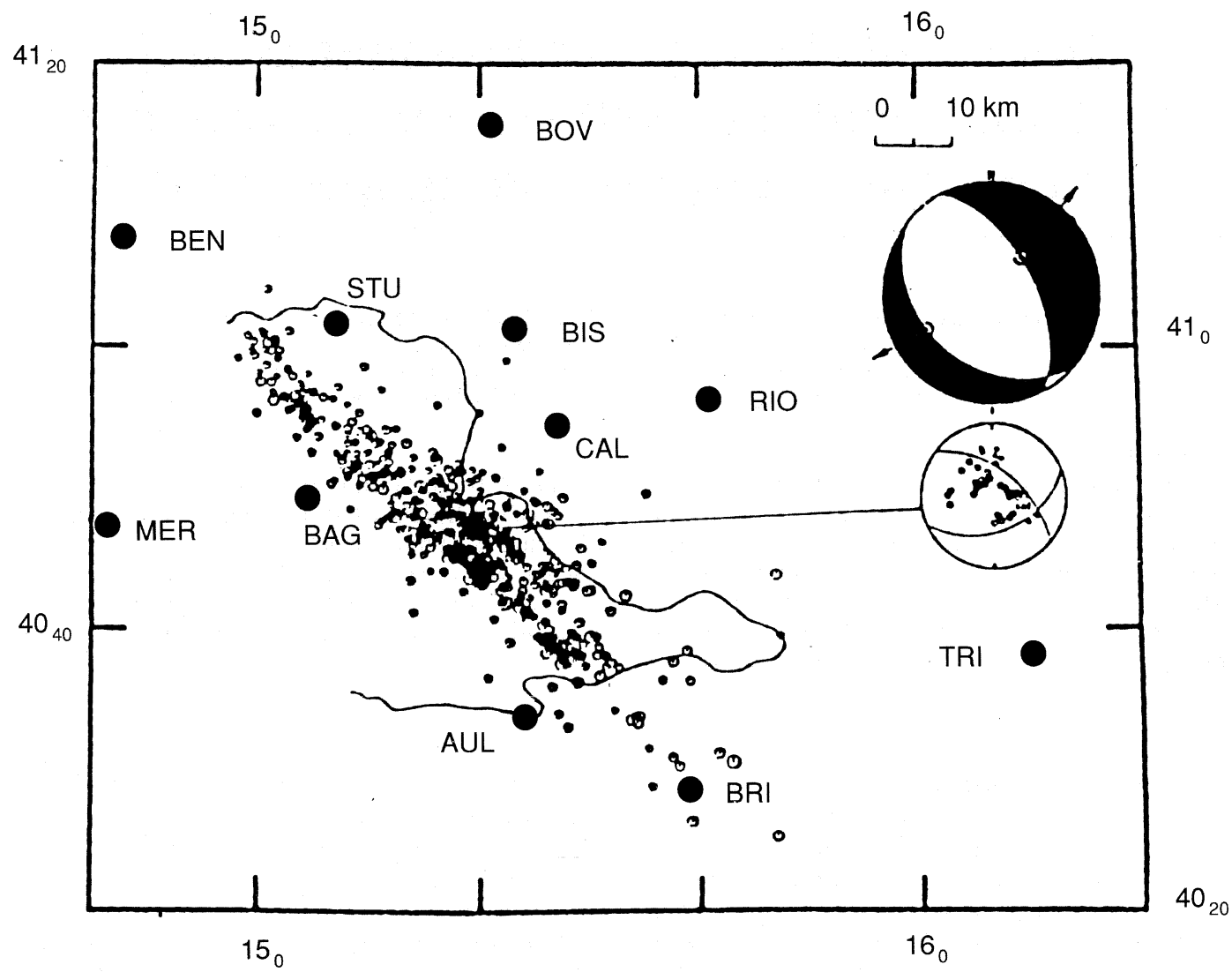

Fig. 1. General view of the faulted area (from Bernard and Zollo, 1989a). The afteshock locations are from Deschamps and King (1983). Dots indicate the strong-motion sites (ENEL). The thin curved line represents the levelling path. The two thick segments are the reported fault trace from Westaway and Jackson (1984). The star is the mainshock epicenter. The mechanism at the top is for long-period body wave tensor inversion (Boschi $e t$ al., 1981). The mechanism at the bottom is computed from teleseismic short-period analysis (Deschamps and King, 1984).

acceleration peak $0.21 \mathrm{~g}$, one of the highest value for the Irpinia earthquake records) (Berardi et al., 1981), and the occurrence of strong aftershocks near this station. Furthermore, the symmetrical shape of the subsidence along the profile necessitates a low dip angle fault. A $30 \mathrm{~cm}$ slip on a $20^{\circ}$ NE dipping plane fits reasonably well the data, and agrees with the teleseismic focal mechanism proposed by WJ. Recently, Vaccari et al. (1990) showed that the triggering times in fig. 2 and the 20 s source location by BZ could model reasonably well the recorded vertical amplitudes for the southern rupture.
The $S$ horizontal polarization in the $(1 \div 2) \mathrm{Hz}$ frequency range appears quite stable for several seconds for the $0 \mathrm{~s}$ and the $40 \mathrm{~s}$ events, which suggests stable mechanisms at the source during the propagation. Analysis of the $S$ polarization is preferred to that of $S$ amplitude because it is less path and site dependent in a carefully selected frequency and distance range. Bernard and Zollo (1987) inverted these polarizations for constraining the source mechanism and locations. The $40 \mathrm{~s}$ event was of particular interest, as 5 stations gave stable $S$ polarizations. The resulting best model, found by an exhaustive search, corresponds to an 

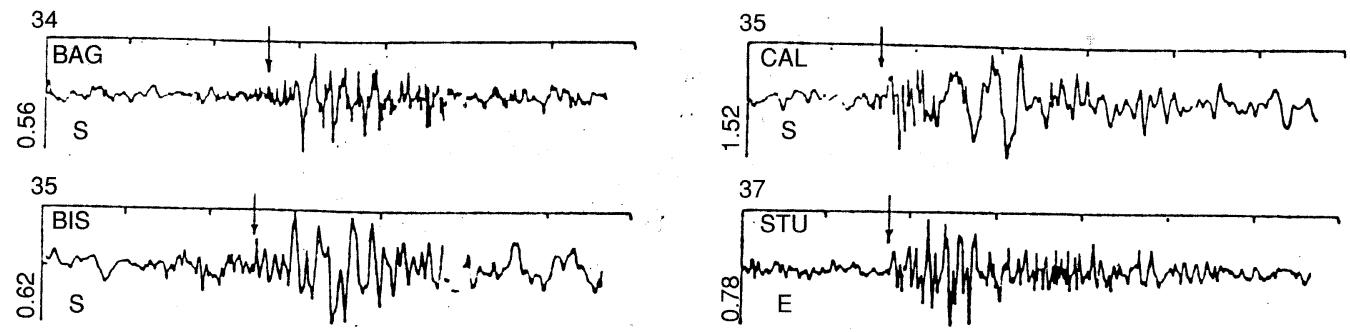

Triggering time deduced from $S 40$ phase picking.

\begin{tabular}{lccc}
\hline & $S 40-t_{0}$ & $\begin{array}{c}\text { Model A } \\
S 40-T 0\end{array}$ & $\begin{array}{c}\text { Model A } \\
t_{0}-T 0\end{array}$ \\
\hline AUL & $38.4 \pm 0.5$ & 52.2 & 13.8 \\
BAG $^{(*)}$ & $41.9-0.2$ & 49.2 & 7.3 \\
BEN & $<40.0$ & 58.1 & 18.1 \\
BIS $\left.^{*}\right)$ & $42.0 \pm 0.5$ & 46.9 & 4.9 \\
BOV $^{(*)}$ & $42.4-2.0$ & 54.7 & 12.3 \\
BRI & $37.8 \pm 0.2$ & 56.7 & 18.9 \\
CAL $^{(*)}$ & $40.2 \pm 0.1$ & 44.5 & 4.3 \\
MER $^{(*)}$ & $46.0-1.0$ & 56.8 & 10.8 \\
RIO $^{*}$ & $43.8-1.0$ & 50.2 & 6.4 \\
STU $^{(*)}$ & $42.2 \pm 0.2$ & 49.8 & 7.6 \\
TRI & $33.2 \pm 1.0$ & 63.5 & 30.3 \\
\hline$S 40-$
\end{tabular}

$S 40-t_{0}$ is observed, $S 40-T 0$ is calculated, and $t_{0}-T 0$ is deduced from them.

${ }^{*}$ An independent estimation of $t_{0}$ is obtained for the station by using the $S 0$ phase picking and the location of the first event.

Time delays between triggering and first $P$ and $S$ arrivals.

\begin{tabular}{lccccc}
\hline \hline & $P 0-T 0^{(*)}$ & $S 0-T 0^{(*)}$ & $\begin{array}{c}\text { Model A } \\
t_{0}-P 0\end{array}$ & $\begin{array}{c}\text { Model A } \\
S 0-t_{0}\end{array}$ & $\begin{array}{c}\text { Observed } \\
S 0-t_{0}\end{array}$ \\
\hline AUL & 5.7 & 10.3 & 8.1 & -3.5 & \\
BAG & 5.4 & 9.8 & 1.9 & 2.5 & $2.6 \pm 0.2$ \\
BEN & 11.2 & 20.2 & 6.9 & 2.1 & $<0.0$ \\
BIS & 6.0 & 10.8 & -1.1 & 5.9 & $5.3 \pm 0.3$ \\
BOV & 10.1 & 18.3 & 2.2 & 6.0 & $4.8 \pm 0.5$ \\
BRI & 8.5 & 15.4 & 10.4 & -3.5 & \\
CAL & 4.4 & 8.0 & -0.1 & 3.7 & $4.2 \pm 0.2$ \\
MER & 9.4 & 17.0 & 1.4 & 6.2 & $5.5 \pm 0.3$ \\
RIO & 7.1 & 12.7 & -0.6 & 6.2 & $5.0 \pm 0.5$ \\
STU & 7.0 & 12.6 & 0.6 & 5.0 & $2.3 \pm 0.2$ \\
TRI & 13.2 & 23.8 & 16.8 & -6.5 & \\
\hline
\end{tabular}

${ }^{(*)}$ Theoretical travel times.

$t_{0}-P 0$ is the delay in the triggering after the $P$ arrival. $S 0-t_{0}$ is the delay in the $S$ arrival after the triggering.

Fig. 2. Top: Strong-motion recordings of the $40 \mathrm{~s}$ rupture. The horizontal components of acceleration $(\mathrm{m} / \mathrm{s})$ at the four closest sites are shown. The time unit is $3 \mathrm{~s}$. Middle: table which reports the accelerometer triggering times deduced from the $S$ phase picking for the 40 s event. Bottom: table which reports the time delays between
triggering and first $P$ and $S$ arrival times. 

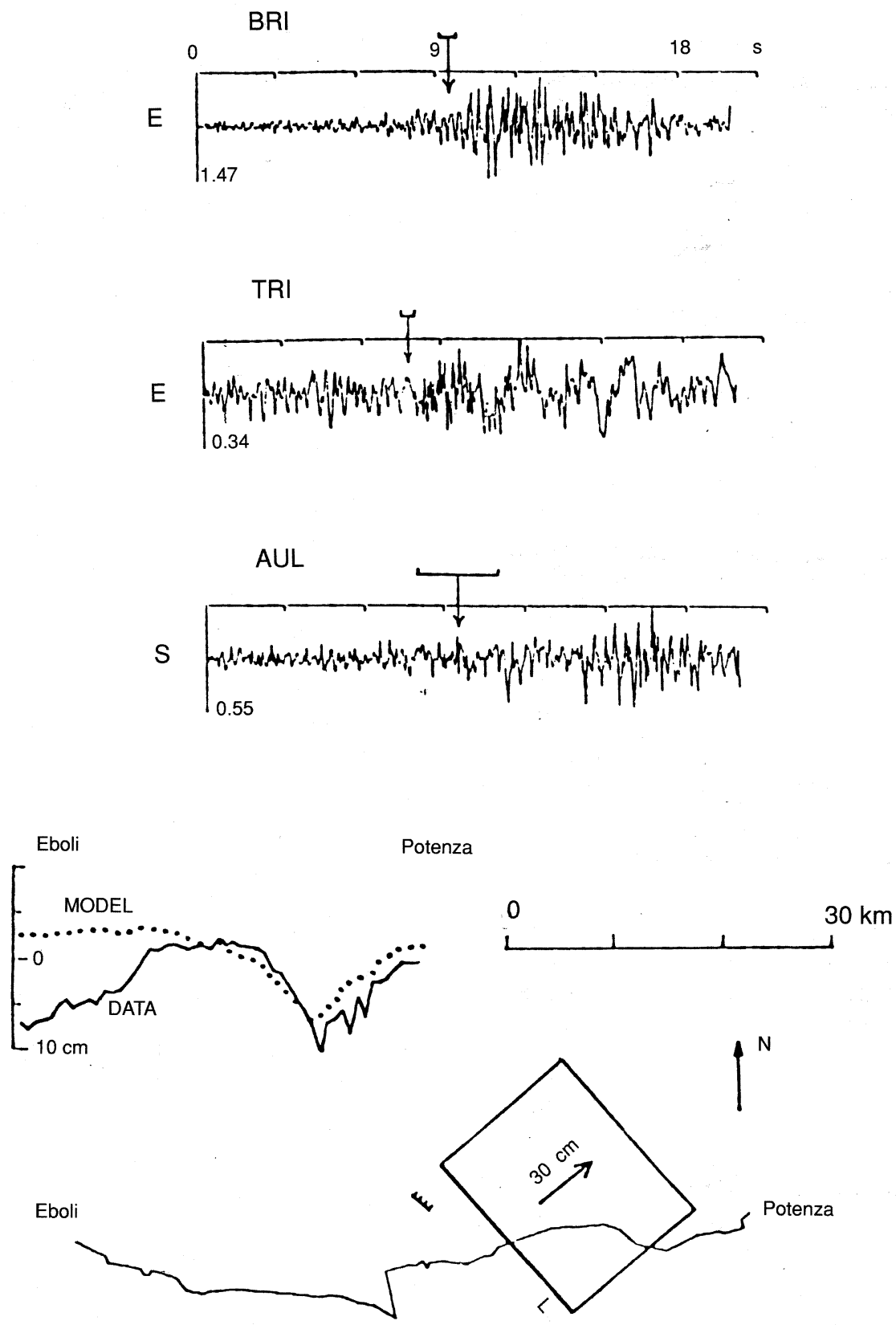

Fig. 3. Top: Strong-motion records of the $20 \mathrm{~s}$ event for stations at South. These three stations triggered about $3 \mathrm{~s}$ after the first nucleation of the rupture, and the high amplitudes correspond to the close $20 \mathrm{~s}$ rupture episode. The arrows (and the associated uncertainty bounds) indicate the first $S$ phases for the $20 \mathrm{~s}$ event, which have been used for locating the event. Bottom: Modeling the vertical deformation near the southern fault. The fault is dipping $20^{\circ}$ toward NE, striking NW. The slip value is $30 \mathrm{~cm}$ on a surface $(15 \times 20) \mathrm{km}^{2}$. 

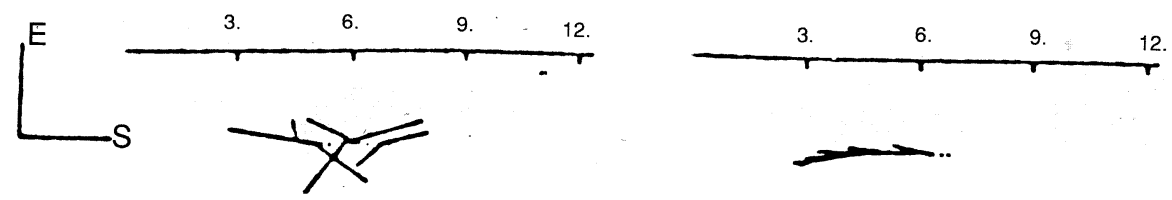

BAG
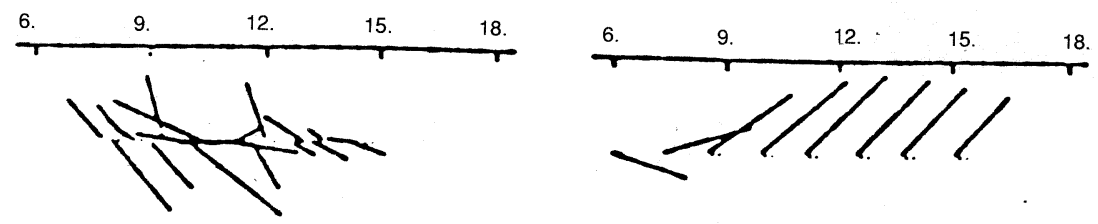

BIS
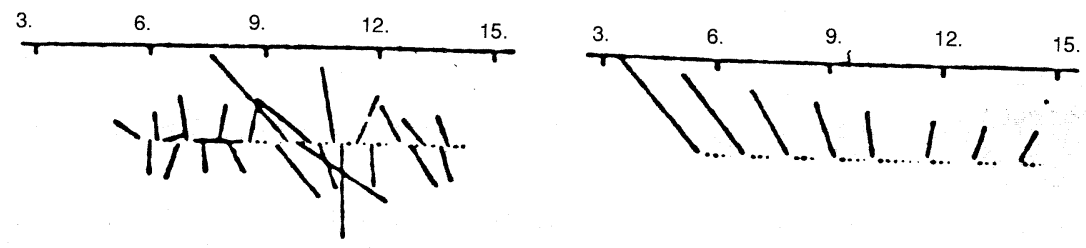

CAL
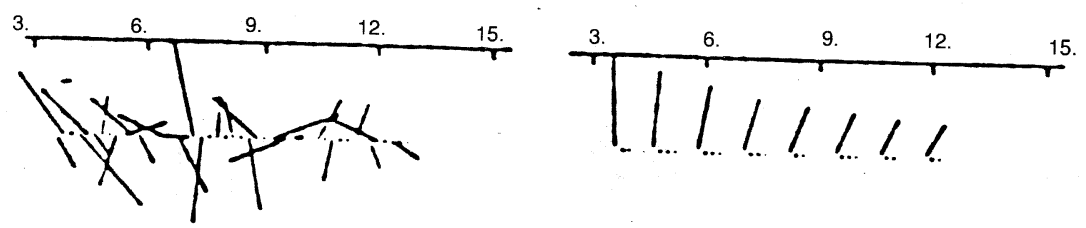

RIO
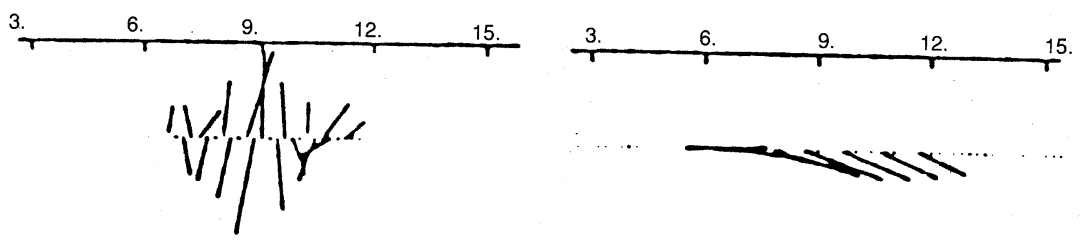

STU

data

synthetic

Fig. 4. Polarigrams associated to the main $S$ arrivals for the $40 \mathrm{~s}$ event. These plots show the projection on the (East, South) plane of the $S$ vector as a function of time. Synthetic polarizations are computed assuming the NE striking fault model as proposed by Crosson et al. (1986) (from Bernard and Zollo, 1986). This model is not able to explain the obseved $S$ polarizations at STU and BIS.

EW striking fault, but the space of possible mechanism parameters was not fully sampled. The NW striking $40 \mathrm{~s}$ fault model, originally proposed by BZ (1989a) from leveling data, appears less likely, although plausible. However, the NE striking fault for the $40 \mathrm{~s}$ event, as is proposed by Crosson etal. (1986), is not acceptable, as it gives $S$ theoretical polarizations incompatible with the 


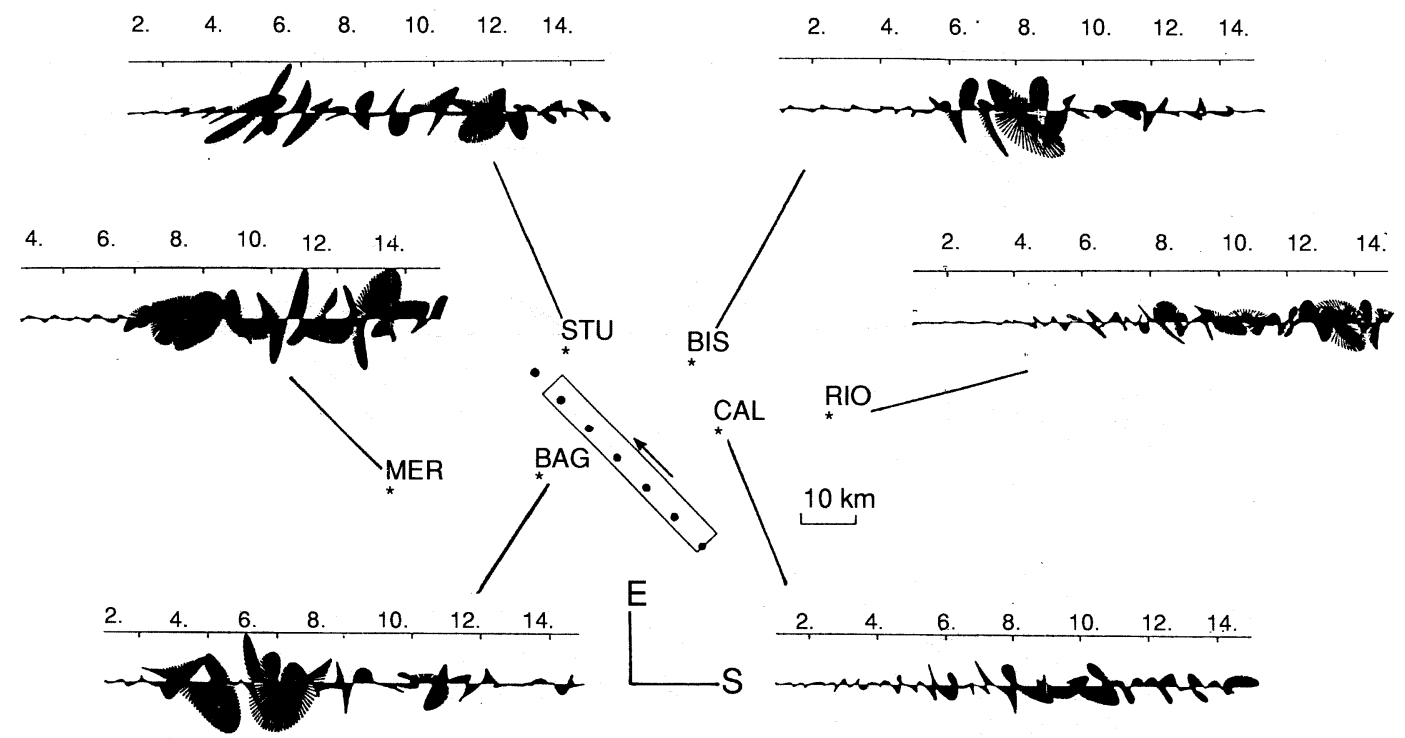

Fig. 5. Modeling the NW rupture by using the $S$ polarization records. Records from the strong-motion sites located closest to the fault have been chosen for this analysis. A line source model is assumed for computing the synthetic polarigrams (fig. 6).

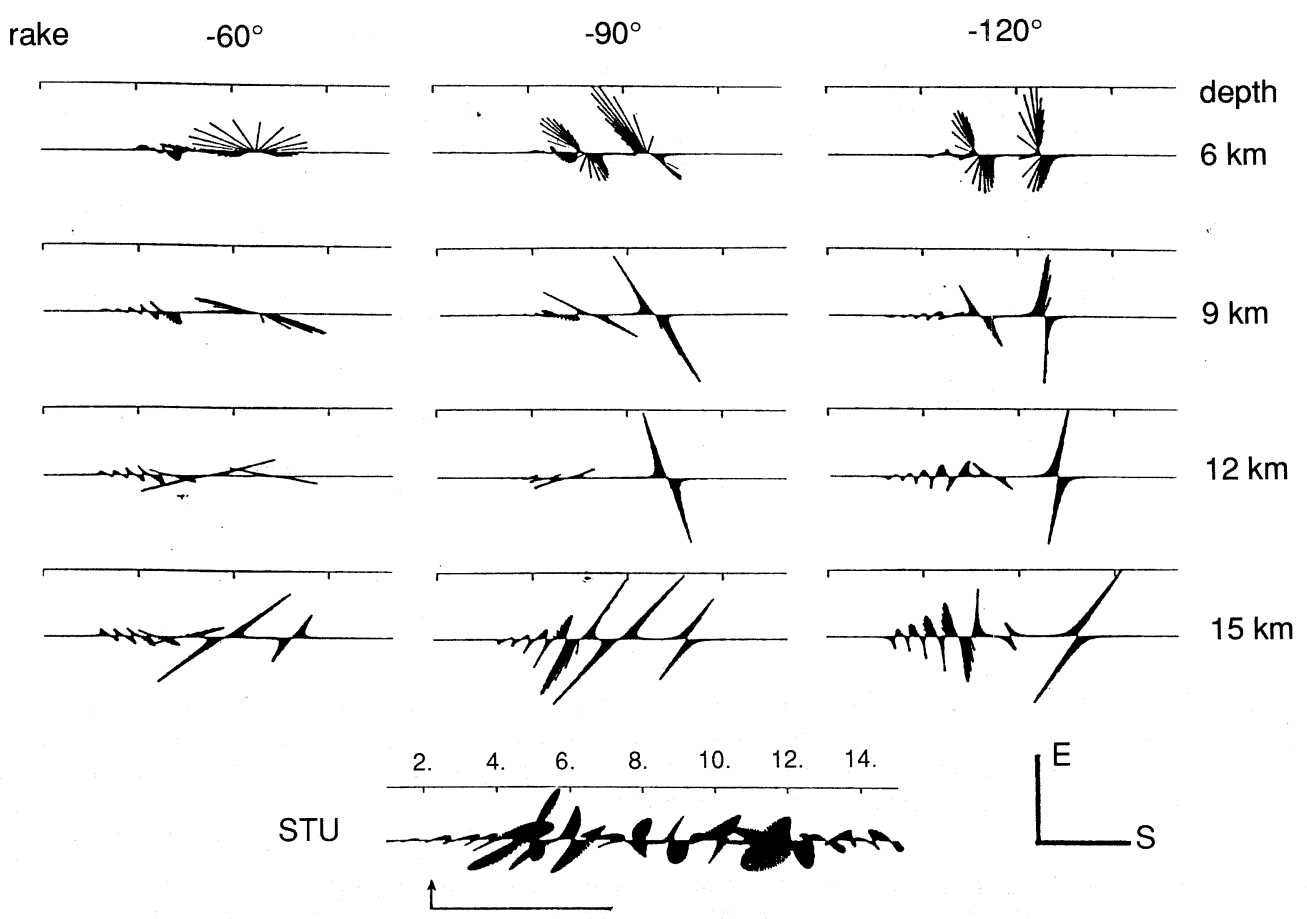

Fig. 6. Modeling the observed polarigram at station STU (Sturno). Theoretical $S$ polarizations are computed by using the ray-theory and a line source rupture model with a constant rupture velocity $(3 \mathrm{~km} / \mathrm{s})$. 
observations at STU and BIS (fig. 4). In this figure, only the horizontal $S$ acceleration peaks are represented, and plotted versus time in the (S,E) frame; the synthetics are generated by a line source a $11 \mathrm{~km}$ in depth (best fitting depth).

Since 1987, the modeling and analysis of the $S$ polarization have been refined for near-source distances (Iannacone and Deschamps, 1989; Bernard and Zollo, 1989b; Zollo and Bernard, 1989;
Zollo, 1990). Trifu et al. (in preparation) reanalyzed the northwestern propagation in terms of the $(1 \div 3) \mathrm{Hz} S$ polarization, testing different mechanisms and source depths. The dip $\left(60^{\circ}\right)$ and strike $\left(\mathrm{N} 45^{\circ} \mathrm{W}\right)$ of the fault plane were assumed equal to the teleseismic focal solutions. The $S$ synthetics for different source depths and rake angles were compared to the records at BAG, CAL, MER, BIS, STU and RIO, in terms of
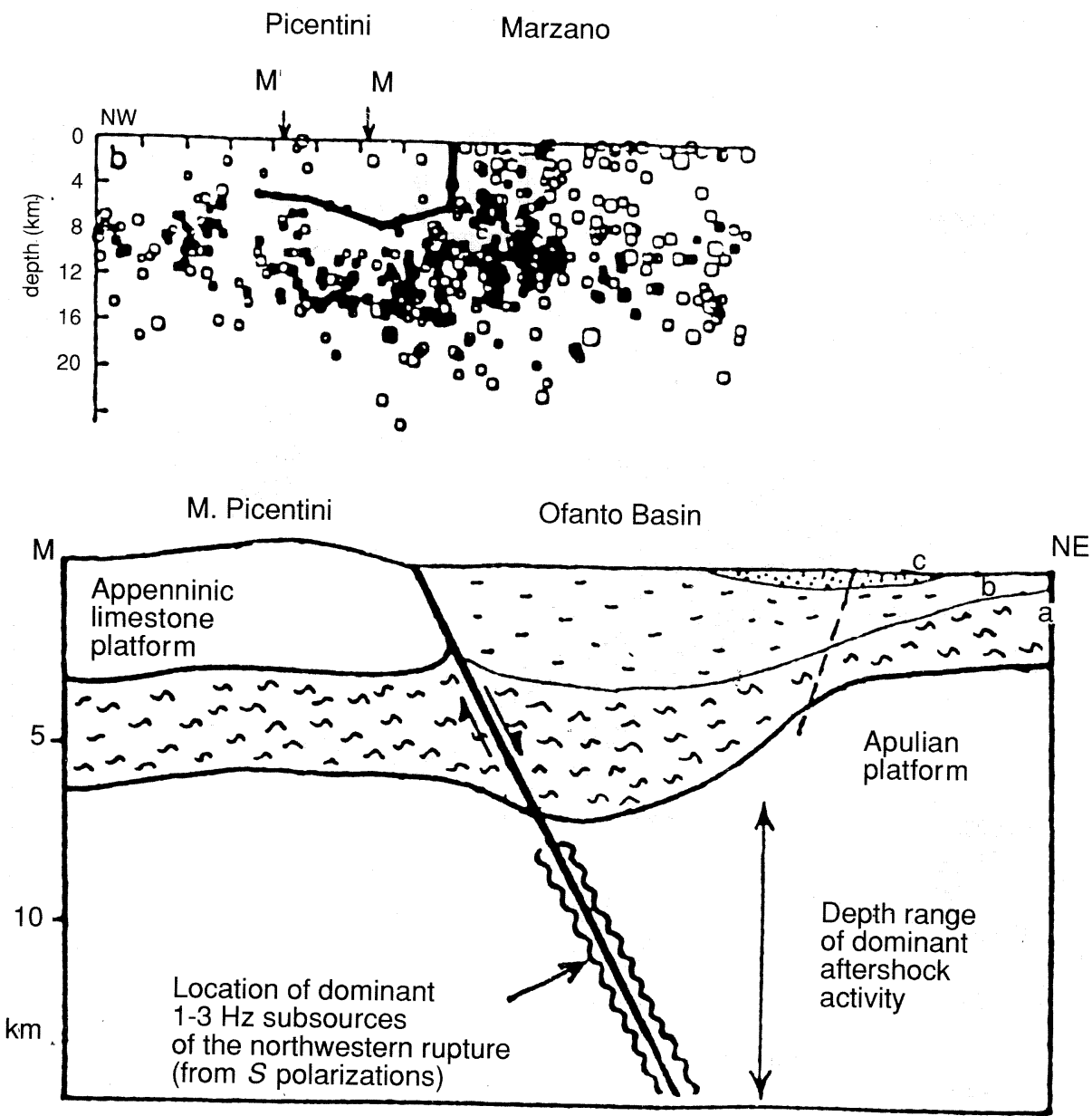

Fig. 7. Top: Aftershock distribution on a vertical plane striking NW. Solid dots are the best located events (from Deschamps and King, 1984). Bottom: Schematic SW-NE geological section along the profile crossing the Mt. Picentini and the Ofanto Basin. This section intersects the aftershocks section (top) at point $M$. The location of the dominant $(1 \div 3) \mathrm{Hz}$ sources are inferred from the $S$ polarization study. Unit «a» between the two platforms corresponds to the Molisano-Lagonegro softer sediments, and units $« b »$ and $« \mathrm{c} »$ to the Tertiary and Quaternary
deposits. 
polarization (fig. 5) (the last point source at the NW was used only for STU). The $S$ records at STU are very constraining (fig. 6): Firstly, the dominant $(1 \div 3) \mathrm{Hz}$ subsources of the first event have to be located below about $8 \mathrm{~km}$ in depth, which coincides with the aftershock distribution NW to the hypocenter (fig. 7, adapted from BZ, 1989); secondly, the mechanism is close to pure normal faulting (slip $90^{\circ} \pm 15^{\circ}$ ); thirdly, the last $10 \mathrm{~km}$ of the northwestern propagation corre- sponds to the rupture of a fault with a significantly different mechanism, as already established by BZ (1987). The synthetic $S$ polarizations produced by the best model for STU fit the observations at BIS and CAL quite well. For BAG, this model predicts unstable polarization, which is indeed observed. For MER and RIO, the larger distances may explain the $S$ polarization instability. The coincidence of an aftershock activity at large depth and the location of the domi-

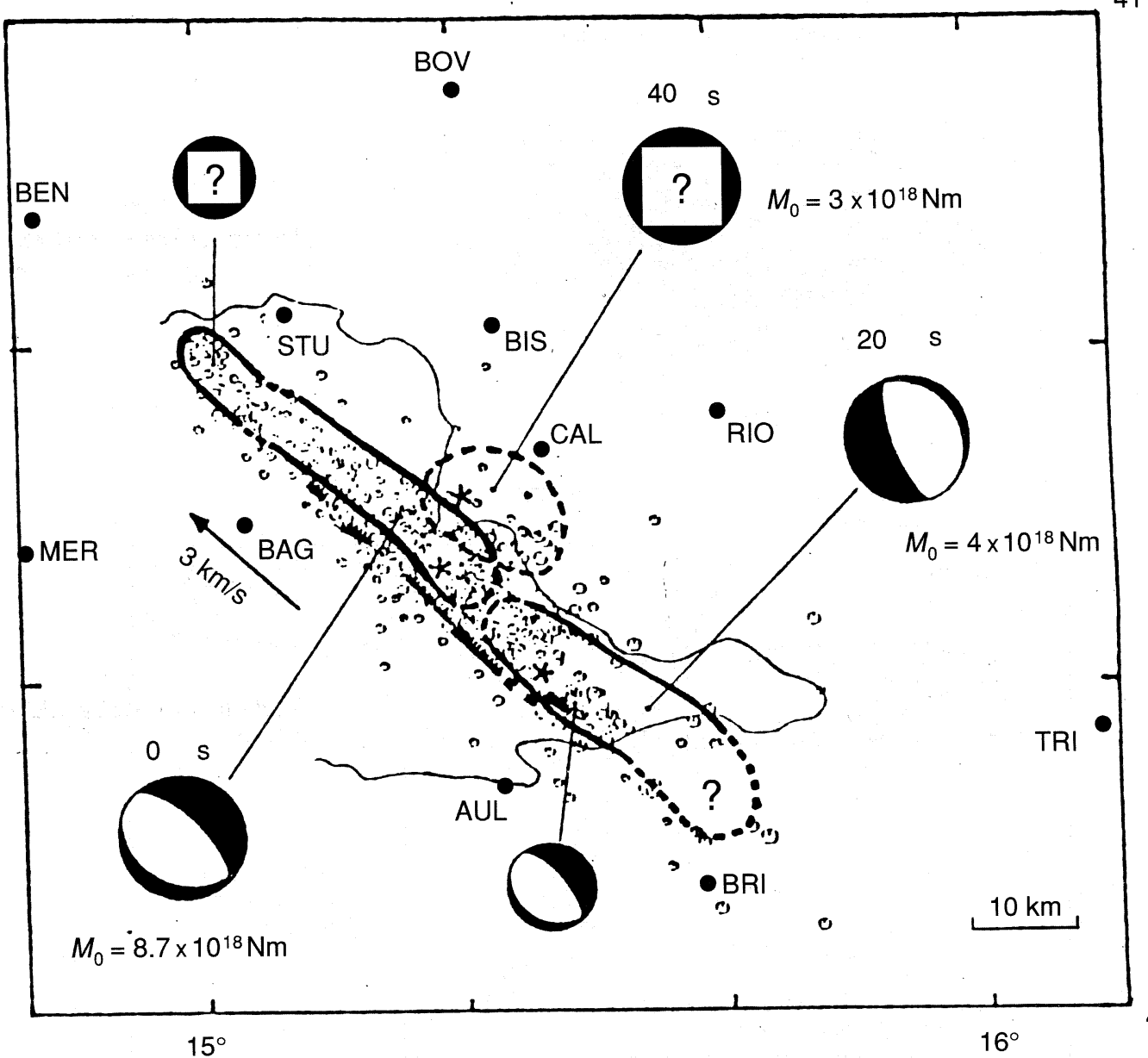

$41^{\circ} 20$

Fig. 8. General view of the faulted area updated after the recent studies on the Irpinia earthquake (see references). Stars indicate the epicenters of the $0 \mathrm{~s}, 20 \mathrm{~s}$ and $40 \mathrm{~s}$ event. The surface breakage evidences from Pantosti and Valensise (1990) are also reported. Fault plane solutions and seismic-moment estimates are from Westaway and Jackson (1987) and Bernard and Zollo (1989). The rupture velocity in the NW sector has been estimated by Bernard and Zollo (1989) by a kinematic study of the NW rupture propagation based on the closest to the fault strong-motion records. Question marks and dashed lines point out the subevent rupture parameters (fault mechanism and extension) which still remain unconstrained by the analyzed data sets. 
nant $(1 \div 3) \mathrm{Hz}$ sources at depth greater than $8 \mathrm{~km}$ suggests a significantly lower strength and/or initial stress of the fault gouge in the deep flysh basin of the Ofanto Valley.

Taking into account the results presented here, together with those recently published by other authors (Vaccari et al., 1990; Pantosti and Valensise, 1990; Siro and Chiaruttini, 1989; Bernard and Zollo, 1991; Siro and Chiaruttini, 1991), we believe that several important questions have not been solved up to now concerning the subsources of the Irpinia 1980 earthquake (see fig. 8):

1) What was the fault mechanism for the last $10 \mathrm{~km}$ at the northwestern end of the first rupture? Is it related to the quaternary basin west of Sturno?

2) Is the $20^{\circ}$ dip of the $20 \mathrm{~s}$ event reliable? If it is, does the slip change abruptly or smoothly in order to reach the $60^{\circ}$ observed at the surface?

3) How far to the SE did the $20 \mathrm{~s}$ rupture propagate? Could the high accelerations at BRI be partly explained by a site effect, rather than by a small distance to the radiating source (BRI is indeed located at the border of a sedimentary basin)? In the case of a rupture passing by BRI, how could one explain the rather low long-period seismic moment of this $20 \mathrm{~s}$ event, in view of the required $40 \mathrm{~km}$ for the southern rupture?

4) What were the location and mechanism of the fault activated at $40 \mathrm{~s}$ ? Are they related to the formation of the Ofanto basin, and in what way? Or are they it related to the graben-like subsidence to the East of Monte Marzano, revealed by leveling data?

The questions above concern the kinematics of the rupture. What can we infer about its mechanics, in terms of rock strength, and geometrical or relaxation barriers? Why and how does the thick flysh layer apparently influence the rupture propagation? Finding the approximate location of the historical earthquakes in the area (1456, $1561,1688,1694,1702,1732,1857,1930)$ (ENEA-ENEL, 1977) relative to the different subsource of the 1980 Irpinia rupture by geological, tectonical and historical research could shed some light on this problem.

A denser accelerometric array and additional leveling lines crossing the Irpinia fault would of course have reduced the major ambiguities that we tried to point out in this paper. But still, the seismological community was quite lucky when the 1980 Irpinia earthquake nicely nucleated in the middle of a relatively dense strong-motion network, and keenly propagated close to existing leveling profiles. Is everything ready for the next large Italian earthquake, or are we expecting to be lucky enough?

\section{REFERENCES}

Arca, S., V. Bonasia, R. Gaulon, F. Pingue, J-C. Ruegg, and R. SCARPA (1983): Ground movements and faulting mechanism associated to the November 23, 1980 Southern Italy earthquake, Boll. Geod. Sci. Affini, XLII, 137147.

BERARDI, R., A. BERENZI and F. CAPOZZA (1981): CampaniaLucania earthquake on 23 November 1980, Accelerometric recordings of the main quake and relating processing, ENEA-ENEL report.

BERNARD, P. and A. Zollo (1986): Analysis of strong ground motion data of the 1980, November 23 Campania-Lucania Earthquake (Italy), in Proceedings of Strasbourg, 1986 Summer School on «Seismic Hazard in Mediterraneen Regions» (in press).

BERNARD, P. and A. Zollo (1987): The Irpinia 1980 earthquake, in Du caractère complexe et agressif des sources sismiques, P. BERNARD, Thesis, University of Paris 7, France.

BERnARD, P. and A. Zollo (1989a): The Irpinia 1980 earthquake: Detailed analysis of a complex normal faulting, $J$. Geophys. Res., 94, 1631-1647.

BERNARD, P. and A. Zollo (1989b): Inversion of near-source $S$ polarization for parameters of double-couple point sources, Bull. Seismol. Soc. Am., 79, 1779-1809.

BernaRD, P. and A. Zollo (1991): Comment on «Source complexity of the 1980 southern Italy earthquake from the analysis of strong ground motion $S$ wave polarization», by Siro, L. and C. ChIARUTTINI, Bull. Seismol. Soc. Am., 81, 278-281.

Boschi, E., F. Mulargia, E. Mantovani, M. Bonafede, A.M. DzIEwonski and J.H. Woodhouse (1981): The Irpinia earthquake of November 23, 1980 (abstr.), EOS Transactions A.G.U., 62, 330.

Crosson, R.S., M. MARTINI, R. SCARPA and S.C. KEY (1986): The southern Italy earthquake of 23rd November 1980: an unusual pattern of faulting, Bull. Seismol. Soc. Am., 76, 381-394.

Deschamps, A. and G.C.P. KING (1983): The Campania-Lucania (southern Italy) earthquake of 23 November 1980, Earth Planet. Sci. Lett., 62, 296-304.

DeschamPS, A. and G.C.P. KING (1984): Aftershocks of the Campania-Lucania (Italy) earthquake of 23 November 1980, Bull. Seismol. Soc. Am., 74, 2483-2517.

ENEA-ENEL (1977): Catalogo dei terremoti italiani dall'anno 1000 al 1975, Delivered to the CNR. Progetto Finalizzato Geodynamica. 
IANNACONE, G. and A. DESCHAMPS (1989): Evidence of shearwave anisotropy in the upper crust of Central Italy, Bull. Seismol. Soc. Am., 7, 2483-2517.

KANAMORI, H. and J.W. GIVEN (1982): Use of long period surface waves for rapid determination of earthquake source parameters, 2 . Preliminary determination of source mechanisms of large earthquakes $\left(M_{\mathrm{S}}>6.5\right)$ in 1980 , Phys. Earth Planet. Inter., 30, 260-268.

PANTOSTI, D. and G. VALENSISE (1990): Faulting mechanism and complexity of the 23 November 1980, Campania-Lucania earthquake, inferred from surface observations, $J$. Geophys. Res., 95, 15319-15341.

Siro, L. and C. ChIARUTTINI (1989): Source complexity of the 1980 southern Italy earthquake from the analysis of strong ground motion $S$-wave polarization, Bull. Seismol. Soc. Am., 79, 1810-1832.

Siro, L. and C. ChiarutTINI (1991): Reply to the Comment on «Source complexity of the 1980 southern Italy earthquake from the analysis of strong ground motion $S$-wave polarization», by BERNARD, P. and A. Zollo, Bull. Seismol. Soc. Am., 81, 282-288.
Trifu, C., A. Herrero, A. Zollo and P. Bernard (1990): Matching the 1-3 Hz Solarization and amplitude of the 1980 Irpinia earthquake: constraints on subsource amplitudes, locations and mechanisms (in preparation).

VACCARI, F., P. SUHADOLC and G.F. PANZA (1990): Irpinia, Italy, 1980 earthquake: Waveform modeling of strong ground motion data, Geophys. J. Int., 101, 631-648.

WESTAWAY, R.W.C. and J. JACKSON (1984): Surface faulting in the southern Italian Campania-Basilicata earthquake of 23 November 1980, Nature, Vol. 312.

WESTAWAY, R.W.C. and J. JACKSON (1987): The earthquake of 1980 November 23 in Campania-Basilicata (southern Italy), Geophys. J. R. Astron. Soc., 90, 375-443.

Zollo, A. (1990): Etude des polarisations et des formes d'onde $S$ en source proche: Détail de la rupture sismique et influence du milieu. Thèse de Doctorat. Université de Paris 7, Paris, France.

ZOLlO, A. and P. BERNARD (1989): $S$-wave polarization inversion of the 15 October 1979, 23:19 imperial Valley aftershock: Evidence for anisotropy and a simple source mechanism, Geophys. Res. Lett., 16, 1047-1050. 